\title{
An Organism Differing from Shigella boydii 13 Only in Its Ability to Produce Gas from Glucose
}

\author{
B. ROWE, R. J. GROSS, AND E. VAN OYE \\ Salmonella and Shigella Reference Laboratory, Central Public Health Laboratory, London NW9 5HT, \\ England, and Institut d'Hygiene et d'Epidemiologie, B-1050 Bruxelles, Belgium
}

\begin{abstract}
It is generally accepted that, except for two biotypes of Shigella flexneri 6 (the Manchester and Newcastle biotypes), all members of the genus Shigella are anaerogenic. Two bacterial isolates are described which have $\mathrm{O}$ antigens identical to those of $S$. boydii 13 and which cannot be distinguished biochemically from typical strains of that biotype except by their ability to produce gas from glucose and other fermentable substances. The relationship between these strains and the typical $S$. boydii 13 is analogous to that between strains of the Manchester biotype and the typical $S$. flexneri 6 .
\end{abstract}

According to the 1958 report of the Enterobacteriaceae Subcommittee (7), members of the genus Shigella do not produce gas from glucose. However, the report recognized that some biotypes of $S$. flexneri 6 possess this character. These biotypes were known previously as the Newcastle bacillus, described by Clayton and Warren (2), and the Manchester bacillus, described by Downie et al. (4).

The present study describes two isolates which possess the $\mathrm{O}$ antigen of $S$. boydii 13 and which cannot be distinguished biochemically from typical strains of that serotype except by their ability to produce gas from glucose and other fermentable substances. Therefore, the relationship between these strains and biochemically typical $S$. boydii 13 is analogous to that between strains of the Manchester biotype and the typical biotype of $S$. flexneri 6 , which is anaerogenic.

Strain E.2054/71 was isolated from the stool of an adult female patient from Nigeria, who was admitted to a hospital in the United Kingdom as the result of an attack of asthma. The patient did not give a history of diarrhea, and the strain was isolated during a routine examination for parasites.

Strain BR.1639 was isolated in Brussels from the stool of a patient with diarrhea, who had recently returned from India; $S$. flexneri $2 b$ was isolated from the same fecal specimen.

The strains were examined biochemically by the methods of Cowan and Steel (3). They were examined further by the methods of Ewing et al. (11) for mutative fermentation of lactose, sucrose, and salicin and by a similar technique for mutative utilization of citrate in Christensen medium.

$\mathrm{O}$ antisera for strains E.2054/71 and BR.1639 were prepared in rabbits, and the two strains were tested for $\mathrm{O}$ antigen identity by using reciprocal absorption techniques.

$\mathrm{O}$ antigen suspension prepared from strain E.2054/71 was tested for agglutination in $\mathrm{O}$ antisera for all Shigella serotypes and for Escherichia coli $\mathrm{O}$ antigens 01 to 0163 . Where reactions occurred, the agglutination titers were determined and the serological relationships were examined by absorption techniques.

$\mathrm{O}$ antigen suspensions of all Shigella serotypes and of $E$. coli $\mathrm{O}$ antigens 01 to 0163 were tested similarly for agglutination in $\mathrm{O}$ antiserum for strain E.2054/71.

Both strains gave the general biochemical reactions of the family Enterobacteriaceae. Their additional reactions (Table 1) differed from those of typical $S$. boyii 13 in the ability to produce gas from glucose. Both strains were ornithine decarboxylose positive, an important observation because in the genus Shigella only $S$. boydii 13 and $S$. sonnei are known to have this character $(8)$.

Mutative fermentation of sucrose, salicin, and lactose was not found, and mutative utilization of Christensen citrate was not demonstrated.

Serological identity of the $\mathrm{O}$ antigens of strains E.2054/71 and BR.1639 was demonstrated by reciprocal absorption techniques. Agglutination tests showed that strain E.2054/71 gave reciprocal cross-reactions with $S$. boydii 13 and $E$. coli $0123 ; S$. flexneri 5 was agglutinated by E.2054/71 antiserum; and E.2054/71 was agglutinated by antiserum for $S$. boydii 9 and $E$. coli 028ac, 098, and 0120 . Reciprocal absorption studies showed that the $O$ antigen of strain E.2054/71 was identical to that of $S$. boydii 13 but failed to show signifi- 
TABLE 1. Biochemical reactions

\begin{tabular}{|c|c|c|}
\hline Determination & E. $2054 / 71^{a}$ & BR. $1639^{a}$ \\
\hline Motility (Craigie) &,- 14 &,- 14 \\
\hline Methyl red test &,+ 2 &,+ 2 \\
\hline Voges-Proskauer reaction &,- 5 &,- 5 \\
\hline Simmons' citrate &,- 7 &,- 7 \\
\hline Christensen citrate &,- 7 &,- 7 \\
\hline Sodium acetate &,- 7 &,- 7 \\
\hline Mucate &,- 14 &,- 14 \\
\hline Malonate &,- 1 &,- 1 \\
\hline Growth in potassium cyanide &,- 2 &,- 2 \\
\hline Indole (Kovacs) &,+ 2 &,+ 2 \\
\hline $\mathrm{H}_{2} \mathrm{~S}$ (triple sugar iron) &,- 7 &,- 7 \\
\hline Gluconate &,- 2 &,- 2 \\
\hline Christensen urea &,- 7 &,- 7 \\
\hline Phenylalanine deaminase &,- 1 &,- 1 \\
\hline Gelatin (stab) &,- 28 &,- 28 \\
\hline Arginine decarboxylase &,- 4 &,- 4 \\
\hline Lysine decarboxylase &,- 4 &,- 4 \\
\hline Ornithine decarboxylase &,+ 1 &,+ 1 \\
\hline$\beta$-galactosidase $(\mathrm{ONPG})^{b}$ &,- 2 &,- 2 \\
\hline Glucose (acid) &,+ 1 &,+ 1 \\
\hline Glucose (gas) &,+ 1 &,+ 1 \\
\hline Lactose &,- 14 &,- 14 \\
\hline Mannitol &,+ 1 &,+ 1 \\
\hline Sucrose &,- 14 &,- 14 \\
\hline Salicin &,- 14 &,- 14 \\
\hline Dulcitol &,- 14 &,- 14 \\
\hline Inositol &,- 14 &,- 14 \\
\hline Adonitol &,- 14 &,- 14 \\
\hline Raffinose &,- 14 &,- 14 \\
\hline Sorbitol &,+ 2 &,+ 1 \\
\hline Arabinose &,+ 2 &,+ 1 \\
\hline Rhamnose &,- 14 &,- 14 \\
\hline Xylose &,- 14 &,- 14 \\
\hline Trehalose &,+ 2 &,+ 1 \\
\hline Inulin &,- 14 &,- 14 \\
\hline Glycerol &,+ 7 & +7 \\
\hline Cellobiose &,- 14 &,- 14 \\
\hline Sorbose &,+ 7 &,+ 3 \\
\hline Maltose &,- 14 &,- 14 \\
\hline
\end{tabular}

${ }^{a}$ Numerals indicate days of incubation.

${ }^{\circ}$ ONPG, $o$-Nitrophenyl- $\beta$-D-galactopyranoside.

cant serological relationships between E.2054/71 and any other cross-reacting $O$ antigens.

Typical strains of $E$. coli may be easily differentiated from Shigella by their motility and by their range of activity in fermentable carbohydrate substrates. However, even in routine work, isolates are frequently encountered that have a fermentation spectrum indistinguishable from that of Shigella. In these circumstances, additional biochemical tests are required; for example, Ewing (8) has shown that strains which decarboxylate lysine cannot be classified as Shigella. Ewing and his colleagues studied over over 2,000 Shigella strains and re- ported that these organisms failed to utilize citrate in Christensen medium. Most biochemically atypical $E$. coli strains may be easily differentiated from Shigella strains by these two tests. Strains E.2054/71 and BR.1639 are nonmotile and have the general biochemical properties of the genus Shigella (7). Furthermore, these strains fail to decarboxylate lysine and do not utilize citrate in Chirstensen medium.

Serologically, strains E.2054/71 and BR.1639 possess an $\mathrm{O}$ antigen that is identical to that of $S$. boydii 13 . Both strains showed some antigenic similarity to $E$. coli $028 \mathrm{ac}, 098,0120$, and 0123 , but absorption studies did not show complete antigen identity. It is recognized that many of the $\mathrm{O}$ antigens of $\boldsymbol{E}$. coli are identical or closely related to those of Shigella (6). It is for this reason that in the identification of Enterobacteriaceae biochemical classification must always be considered in addition to the serological findings.

Freshly isolated shigellae invade epithelial cells; this property may be demonstrated by the Sereny test (13) using the guinea pig eye conjunctivum. However, there is abundant evidence that this property is not restricted to shigellae and that certain strains of $E$. coli are invasive and give positive results in this test (5). For this reason, tests for cellular invasiveness are of little value in the differentiation of $E$. coli and Shigella.

Sachs (12) described an aerogenic organism known as enterobacterium A12, and subsequent studies by Carpenter (1) and SzturmRubinstein et al. (15) showed that strains of this organism gave the general biochemical reactions of Shigella. These workers considered the A12 organism to be an aerogenic biotype of the $S$. boydii subgroup and reported that these organisms possessed the $O$ antigens of $S$. boydii 14. However, Ewing and Hucks (9) showed that strains of enterobacterium A12 differed from typical strains of $S$. boydii 14 in that they failed to ferment mannitol. The same authors (10) showed that the $\mathrm{O}$ antigens of A12 strains were identical to those of $E$. coli 032 and they regarded the A12 strains as aberrant members of the genus Escherichia. Edwards and Ewing (6) subsequently reported that A12 strains utilized Christensen citrate mutatively and could, in their view, no longer be considered as strains of $S$. boydii.

Stypulkowska (14) described a variant of $S$. dysenteriae 3 which differed from typical strains in that it fermented mannitol and produced gas from glucose. 
Strains E.2054/71 and BR.1639 resemble typical strains of $S$. boydii 13 in their ability to ferment mannitol and their failure to utilize Christensen citrate mutatively. These strains cannot be excluded from the genus Shigella by currently accepted criteria.

We are indebted to I. Ørskov and F. Ørskov of the W.H.O. International Escherichia Centre, Statens Seruminstitut, Copenhagen, who confirmed our serological findings.

\section{REPRINT REQUESTS}

Address reprint requests to: Dr. B. Rowe, Salmonella and Shigella Reference Laboratory, Central Public Health Laboratory, Colindale Ave., London NW9 5HT, England.

\section{LITERATURE CITED}

1. Carpenter, K. P. 1961. The relationship of the Enterobacterium A12 (Sachs) to Shigella boydii 14. J. Gen. Microbiol. 26:535-542.

2. Clayton, F. H. S., and S. H. Warren. 1929. An unusual, bacillus recovered from cases presenting symptoms of dysentery. J. Hyg. 28:355-362.

3. Cowan, S. T., and K. J. Steel. 1965. Manual for the identification of medical bacteria. Cambridge University Press, Cambridge.

4. Downie, A. W., E. Wade, and J. A. Young. 1933. An organism resembling the Newcastle type of dysentery bacillus associated with cases of dysentery. J. Hyg. 33:196-203.

5. DuPont, H. L., S. 'B. Formal, R. B. Hornick, M. J.
Snyder, J. P. Libonati, D. G. Sheahan, E. H. LaBrec, and J. P. Kalas. 1971. Pathogenesis of Escherichio coli diarrhoea. N. Engl. J. Med. 285:1-19.

6. Edwards, P. R., and W. H. Ewing. 1972. Identification of Enterobacteriaceae. Burgess Publishing Co., Minneapolis.

7. Encerobacteriaceae Subcommittee. 1958. Report of the Enterobacteriaceae Subcommittee. Int. Bull. Bacteriol. Nomencl. Taxon. 8:25-70.

8. Ewing, W. H. 1971. Biochemical reactions of Shigella. U.S. Department of Health Publication no. 72-8081. U.S. Government Printing Office, Washington, D.C.

9. Ewing, W. H., and M. C. Hucks. 1950. Two intermediate members of Enterobacteriaceae. J. Bacteriol. 60:367-368.

10. Ewing, W. H., and M. C. Hucks. 1952. Four new provisional serotypes of Shigella. J. Immunol. 69:575-580.

11. Ewing, W. H., R. W. Reavis, and B. R. Davis. 1958. Provisional Shigella serotypes. Can. J. Microbiol. 4: 89-107.

12. Sachs, A. 1943. A report on an investigation into the characteristics of new types of non mannitol-fermenting bacilli isolated from cases of bacillary dysentery in India and Egypt. J. R. Army Med. Corps 80:92-99.

13. Sereny, B. 1955. Experimental shigella keratoconjunctivitis. Acta Microbiol. Hung. 2:293-296.

14. Stypulkowska, H. 1964. An untypical strain of Shigella dysenteriae 3 isolated in Poland. Med. Dosw. Mikrobiol. 16:147-154.

15. Szturm-Rubinstein, S., D. Piechaud, and G. Allos. 1962. A propos d'une variete gazogene de Shigella boydii 14. Ann. Inst. Pasteur Paris 103:303-305. 